\title{
Vibration Behaviour Control of a Fabricated One- Passenger Electric Vehicle with Either Mechanical or Air Suspension
}

\author{
Shawki A. Abouel-seoud \\ Automotive and Tractors Engineering Department, Helwan University, Cairo, P.O.Box 11718, Egypt
}

\begin{abstract}
(Received 20 October 2017; accepted 23 July 2018)
Vehicle vibration transmission associated with the dynamic system depends on the frequency and direction of the input motion and the characteristics of vehicle suspension system and the seat from which the vibration exposure is received. A fabricated one-passenger electric vehicle equipped by a coil spring (mechanical) suspension system is introduced in this study. An air suspension system is used to replace the coil spring suspension system to improve ride comfort performance and intelligent classical adaptive neuro-fuzzy inference system controller is used to control the vehicle seat performance parameters. Accelerometers are mounted on the seat pan and seat base (floor) when measuring vertical acceleration. Data is frequently weighted according to standard BS 6841 in order to model the human response to vibration in terms of location and direction. The Simulink model is developed in Matlab software with the adaptive neuro-fuzzy inference system controller for the vehicle seat weighted vibration acceleration control. The results indicate that the predicted vibration acceleration can track the target vibration acceleration very well. Moreover, the values of the crest factor and kurtosis for the vehicle equipped by air suspension system are lower than those for the vehicle equipped by mechanical suspension system. Furthermore, the seat effective amplitude transmissibility for the fabricated vehicle with air suspension behaves lower value than that for mechanical suspension.
\end{abstract}

\section{NOMENCLATURE}

\begin{tabular}{|c|c|}
\hline RMS & Root-mean-square \\
\hline VDV & Vibration dose value \\
\hline IRI & International roughness index \\
\hline$C F$ & The crest factor \\
\hline Kurt & Kurtosis \\
\hline$W_{i}(f)$ & Vertical vibration filter \\
\hline$N$ & The number of data points \\
\hline$x(n)$ & The amplitude of the signal at the $\mathrm{n}^{\text {th }}$ point \\
\hline$n$ & The number of discrete data \\
\hline$V(\mathrm{~km} / \mathrm{h})$ & The vehicle forward speed \\
\hline$(a)_{r m s}$ & The vehicle floor RMS vibration acceleration \\
\hline$a_{w}$ & The frequency-weighted acceleration \\
\hline$T$ & The duration of measurement \\
\hline SEAT & Seat Effective Amplitude Transmissibility \\
\hline $\bar{x}$ & The average of total data \\
\hline $\mathrm{RMS}_{\text {seat }}$ & $\begin{array}{l}\text { Frequency-weighted RMS accelerations } \\
\text { on the vehicle seat }\end{array}$ \\
\hline $\mathrm{RMS}_{\text {floor }}$ & $\begin{array}{l}\text { Frequency-weighted RMS accelerations } \\
\text { on the vehicle floor }\end{array}$ \\
\hline ANFIS & Adaptive Neuro Fuzzy Inference Scheme \\
\hline ORS & The input signal \\
\hline $\mathrm{CORS}_{\mathrm{d}}$ & Actual output of the ANFIS \\
\hline FSO & The offside front suspension vibration acceleration \\
\hline FSN & The nearside front suspension vibration acceleration \\
\hline RSO & The offside rear suspension vibration acceleration \\
\hline RSN & The nearside rear suspension vibration acceleration \\
\hline ORS & The vehicle seat pan vibration acceleration \\
\hline URS & The vehicle under seat (floor) vibration acceleration \\
\hline$E_{i}$ & The cost function error \\
\hline RMSE & Root mean squared error \\
\hline$K$ & The membership functions for each input \\
\hline$R$ & The number of fuzzy rules \\
\hline$N_{i}$ & Adaptive Neuro Fuzzy Inference Scheme inputs data \\
\hline
\end{tabular}

\section{INTRODUCTION}

A comfortable ride is essential for a vehicle to obtain passenger satisfaction. In this view, vehicle manufacturers are constantly seeking to improve vibration comfort. Many factors influence the transmission of vibration to and through the body. Transmission associated with the dynamic system depends on the frequency and direction of the input motion and the characteristics of the vehicle suspension system and the seat from which the vibration exposure is received. Oscillatory responses are analysed by means of a bus oscillatory model with linear characteristics and three degrees of freedom, with excitation by the Power Spectral Density (PSD) of the roughness of asphalt-concrete pavement in good condition. This analysis is conducted through a simulation, in frequency domain, using statistical dynamics equations. A program created in the software pack MATLAB is used to analyse the transfer functions, spectral density and RMS of oscillatory parameters. $^{1,2}$ The results of the analysis show that the parameters, which ensured good oscillatory comfort for the driver, were conflicting with the parameters which ensured the greatest stability of the bus and the corresponding wheel travel. In terms of the driver's oscillatory comfort, the bus suspension system should have a spring of small stiffness and a shock absorber with a low damping coefficient. In terms of active safety, it should have a spring of small stiffness and a shock absorber with a high damping coefficient, while minimum wheel motion requests for springs of great stiffness and shock absorbers with a high damping coefficient.

A new pneumatic spring that allows for tuning the stiffness and ride height independently and continuously is pre- 
sented. The proposed pneumatic spring comprises a doubleacting pneumatic cylinder, two accumulators, and a tuning subsystem. This new pneumatic spring is highly capable of improving vehicle performance and comfort on any road condition according to a driver's preference or adaptations in real time. The mathematical model is established based on principles of thermo and fluid dynamics. An experimental setup has been designed and fabricated for testing and evaluating the proposed pneumatic spring, spring modeling and validate the tuning capabilities of the new pneumatic spring. ${ }^{3-5}$ This new pneumatic spring provides a more flexible suspension design alternative for meeting various conflicting suspension requirements for ride comfort and performance.

A seat exposed to increasing magnitudes of vibration is initially friction locked. As the vibration magnitude is increased, the seat begins to 'break away' producing jolting on the seat surface and causes the SEAT (seat effective amplitude transmissibility) value to increase. As friction become less dominant, the SEAT value decreases and the seat acts to reduce the vibration on the seat surface. The SEAT value increases as the end-stop impacts cause severe vibrations at the seat surface. An evaluation of old and new seat suspension systems is given. It starts approximately 20 years ago, when the scissor system as a supporting structure of the suspension system took strong hold. Only the conventional type of seat is taken into consideration ('full travel' type of suspension with free travel of $100 \mathrm{~mm}$ ). ${ }^{6}$ This mechanism proved to be very safe and was low in production cost. The same supporting structure was used in all seats under investigation. ${ }^{7}$

Vehicles driven by in-wheel motors have been receiving more and more attention. However, due to the introduction of in wheel motors, the ratio between unsprung and sprung mass is increased. The influence of the change on ride comfort of vehicles driven by in-wheel motors, an 11-degree of freedom of vehicle ride comfort model will be presented and studied with Matlab/Simulink. ${ }^{8,9}$ Then, road tests will be conducted to corroborate the simulation results. It can be obtained that the vehicle ride comfort becomes poor with the increasing unsprung mass. Finally, semi-active air-suspension proportionalintegral-derivative control system will be proposed to improve the vehicle ride comfort. Through the simulation results, one can conclude that the proportional-integral-derivative control system for air suspension is feasible and effective to improve the ride comfort of the vehicles driven by in-wheel motors.

In this study, a fabricated one-passenger electric vehicle equipped by a coil spring suspension system was designed. An air spring suspension system was used to replace the coil spring (mechanical) suspension system to improve rid comfort performance parameters from the controlled vehicle seat vertical vibration responses. The relevant system parameters are detailed described. The intelligent, classical, and adaptive neuro-fuzzy inference system (ANFIS) controller was designed according to underlying principles which can be easily applied on this fabricated vehicle. For this special study, a feed-forward compensator is introduced to improve the performance. The frequency range is being set up to $30 \mathrm{~Hz}$ and the road surface is paved concrete texture with vehicle forward speed of $10 \mathrm{~km} / \mathrm{h}$.

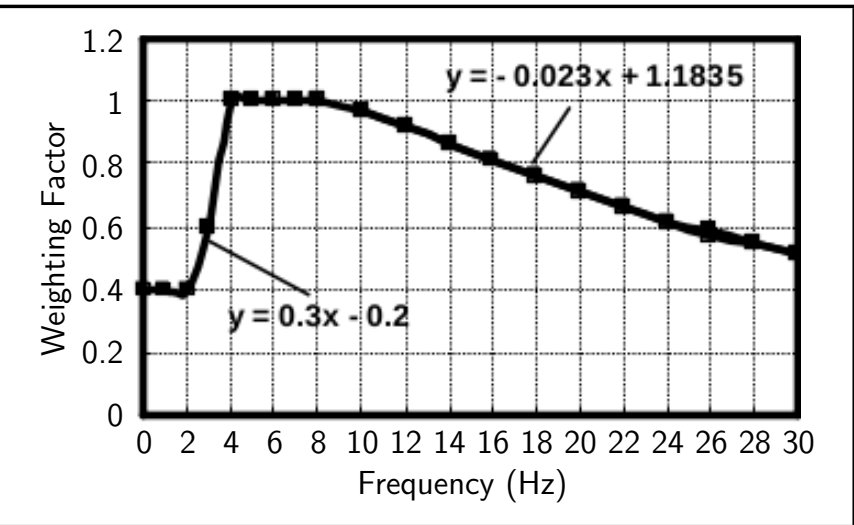

Figure 1. BS 8641 frequency weighting filter.

\section{BS 8641 FREQUENCY WEIGHTING FILTER}

\subsection{Road Test Data}

The best methodology for comfort evaluation, giving a single number value, was determined. A single number estimate of vibration severity required that the motion be weighted according to the relative importance of different physical variables: magnitude, frequency and duration. Using filters $W_{i}(f)$ for vertical axis (bounce) as proposed in the British Standard BS 6841 (equivalent to the ISO 2631-1 vertical vibration filter) (Fig. 1) for whole-body vibration evaluation, ${ }^{10,11}$ all frequencies from the vehicle body vibration acceleration data with lower contribution to the discomfort feeling were lowered in value, where frequencies with high contribution were raised in value. The former are mainly the frequencies under $4 \mathrm{~Hz}$ and above $8 \mathrm{~Hz}$.

\subsection{Vibration Signal}

\subsubsection{Crest factor}

The crest factor is defined as the ratio of the peak value to the RMS of the signal. The crest factor $(\mathrm{CF})$ was calculated to determine the most suitable method of analysis (i.e. RMS or VDV), and was given by:

$$
C F=\left|\frac{\max \left(a_{w}\right)}{a_{w r m s}}\right| .
$$

\subsubsection{Kurtosis of vibration signals}

Kurtosis (Kurt) is defined as the fourth statistical moment signal, known as a global statistical parameter, that is highly sensitive to the impulsiveness of the time-domain data. For discrete data sets was approximated by:

$$
\text { Kurt }=\frac{(1 / N) \sum_{n=1}^{N}(x(n)-\bar{x})^{4}}{\left[(1 / N) \sum_{n=1}^{N}(x(n)-\bar{x})^{2}\right]^{2}} ;
$$

where $N$ was the number of data points taken in the signal, $x_{(n)}$ was the amplitude of the signal at the $\mathrm{n}^{\text {th }}$ point, and $\bar{x}$ was the mean value of all amplitudes. 
The kurtosis statistical parameter was measured in different speeds as a road surface characteristic parameter. The variation due to road surface and speed conditions will be evaluated as well. The kurtosis value was approximately 3.0 for a Gaussian distribution. Higher kurtosis indicated the existence of numerous extreme data values, inconsistent with a Gaussian distribution, while lower than 3.0 designated a relatively flat distribution.

\subsubsection{International road roughness index}

The three main sources of vibration transmitted to the vehicle driver are: road roughness, vehicle engine and driver's behaviour (including choice of speed). Within reasonable variations in these factors, road roughness plays a considerably greater part than the other two. ${ }^{12}$ In vehicle research into comfort quality, all the three sources are playing important role. To include the road roughness in this study, the International roughness index (IRI) was used. It was a general pavement condition indicator that summarized the roughness qualities that affected tractor response and was most appropriate when a roughness measure was desired that relates to overall ride quality and overall surface condition. ${ }^{13}$ The IRI value was defined approximately from the following equation.

$$
\frac{(a)_{r m s}}{I R I}=0.16\left(\frac{\nu}{80}\right)^{\frac{1}{2}}
$$

where $\nu(\mathrm{km} / \mathrm{h})$ was the tractor forward speed and $(a)_{r m s}$ was the vehicle floor RMS acceleration vibration $\left(\mathrm{m} / \mathrm{s}^{2}\right)$.

\subsection{Frequency Analysis}

Vibration evaluations were performed according to the recommendations in the BS $6841 .{ }^{11}$ This involved the application of frequency weightings, multiplication of factors to allow for different sensitivities of the body in different axes, calculation of root-mean-square (RMS), and vibration dose value (VDV).

The frequency weighted data was converted into a comfort value using RMS. or VDV. BS $6841^{10}$ proposed using RMS when $\mathrm{CF}$ is less 6. RMS is the time dependency according to the ISO 2631. ${ }^{11}$ This is a very complex procedure and it was not appropriate for signals containing shocks.

$$
R M S=\sqrt{\frac{1}{T} \int_{0}^{T} a_{w}^{2}(t) \mathrm{dt}}
$$

where $a_{w}(t)$ was the frequency-weighted acceleration. According to the BS $6841,{ }^{10}$ vibration magnitudes and durations that produce RMS in the region of $0.825 \mathrm{~m} / \mathrm{s}^{2}$ A (8) will usually cause severe discomfort. The exposure period required for the RMS to reach a tentative action level of $0.825 \mathrm{~A}(8)$ can be calculated as:

$$
T_{0.825_{A(8)}}=\frac{8 \times 0.825^{2}}{(a)_{r m s}^{2}} ;
$$

where $(a)_{r m s}$ was the weighted RMS vibration magnitude.

The data acquired was measured for $10 \mathrm{~min}$. However, this was measured in such a way as to represent the vibration levels experienced by the passenger related to the normal 8-hour work period. The required parameters were then computed and extrapolated to cover the entire duration of exposure. Subsequently, the weighted RMS parameter was then computed.

\subsection{Seat Effective Amplitude Transmissibility}

Seat comfort is usually assessed by making vibration measurements on the surface of the tractor seat based on the BS 6841. Seat-isolation performance was indicated by Seat Effective Amplitude Transmissibility (SEAT) values, which can be calculated from frequency-weighted RMS accelerations on the vehicle seat pan surface and vehicle floor, $\mathrm{RMS}_{\text {seat }}$ and $\mathrm{RMS}_{\text {floor }}$, respectively:

$$
S E A T \%=100 \times \frac{R M S_{\text {seat }}}{R M S_{\text {floor }}} .
$$

The SEAT value is a measure of how well the transmissibility of a seat is suited to the spectrum of entering vibration, considering the sensitivity of the seat occupant to different frequencies. SEAT values less than $100 \%$ indicate isolation or attenuation of vibration. It allows for the comparison of seat performance on a variety of road surfaces. ${ }^{11}$

\section{VEHICLE SEAT CONTROL PERFORMANCE PARAMETERS}

\subsection{Adaptive Neuro Fuzzy Inference Scheme Technique}

The final output was the weighted average of each rule's output. Adaptive Neuro Fuzzy Inference Scheme (ANFIS) is functionally equivalent to a Takagi-Sugeno (T-S) fuzzy inference system. By using stipulated input-output training data pairs, ANFIS tunes the membership functions and other associated parameters by back propagation gradient descent and least square type method, respectively. Such methodologies make the ANFIS modeling more systematic and less reliant on expert knowledge, thus more objective. The corresponding equivalent ANFIS structure and learning process can be found in. $^{14,15}$

\subsection{Training Process for ANFIS Model}

The ANFIS model mainly consisted of the NF network placed in series with the vehicle. The training process for obtaining the model of the vehicle is shown in Fig. 2, where the input and output data set was used to reflect the input-output characteristics of the vehicle. The training data set was used based on: FSO, FSN, RSO, RSN, ORS, URS, CORS d $_{\text {, where }}$ FSO was the offside front suspension vibration acceleration, FSN was the nearside front suspension vibration acceleration, RSO was the offside rear suspension vibration acceleration, RSN was the nearside rear suspension vibration acceleration, ORS was the vehicle seat pan vibration acceleration, URS was the vehicle under seat (floor) vibration acceleration, and $C O R S_{d}$ was the desired vehicle seat acceleration. The ANFIS network was trained by the least square estimation method to minimize the cost function error $\left(E_{i}\right)$ defined by: 


$$
E_{1}=\sum_{i=1}^{N}\left(O R S-C O R S_{d}\right) .
$$

ORS was the input signal and $\mathrm{CORS}_{\mathrm{d}}$ the corresponding actual (desired) output of the component's ANFIS. The iterative learning tuner was designed to improve the tracking performance of inverse-ANFIS control which repeats the desired task over a finite interval.

\subsection{Inputs Selection}

Prior to training the individual ANFIS model, the number of input membership functions was determined, which is an important factor in the initial condition. In the case of ANFIS which has $N_{i}$ inputs and $K$ membership functions for each input, the number of fuzzy rules $R$ was:

$$
R=K^{N_{1}}
$$

It was seen from Eq. (8) that too many inputs and input membership functions will lead to substantial increase of inference rules and thus increase training time and computer memory space consumption. Therefore, it was necessary to do input selection that found the priority of each candidate inputs and used them accordingly. A quick and straightforward way of input selection for neuro-fuzzy modeling was to use ANFIS. The proposed input selection method assumed that the ANFIS model with the smallest RMSE (root mean squared error) after one epoch of training had a greater potential of achieving a lower RMSE when given more epochs of training. In this study, five models had been tried with different combinations of two inputs and trained them with a single pass of the least square method. ${ }^{16}$ After several trials, the smallest training error was achieved when the inputs were FSO, FSN, RSO, RSN, ORS, URS at the current time step and CORS from previous time step to produce output $\mathrm{CORS}_{\mathrm{d}}$ at the current time step. Then the selected inputs were trained using the hybrid learning rule to tune the membership functions as well.

\subsection{Adaptive Neuro Fuzzy Inference Scheme Controller Design}

\subsubsection{Background}

In this study, Adaptive Neuro Fuzzy Inference Scheme (ANFIS) technique was used to design a controller to reduce the vibration of the vehicle seat pan by control the vibration response transmitted from both engine and road surface. The design process is as follows: A neuro-fuzzy model for the vehicle seat pan was built to represent the relation between the variation of the vibration acceleration transmitted through to driver seat pan i.e. (obtain outputs given the inputs).

\subsubsection{Training neuro-fuzzy vehicle seat pan con- troller}

Given input/output data sets, ANFIS constructs Fuzzy Inference System (FIS) whose membership function parameters were adjusted using a back-propagation algorithm. The size of input-output data needed to be large enough and cover all

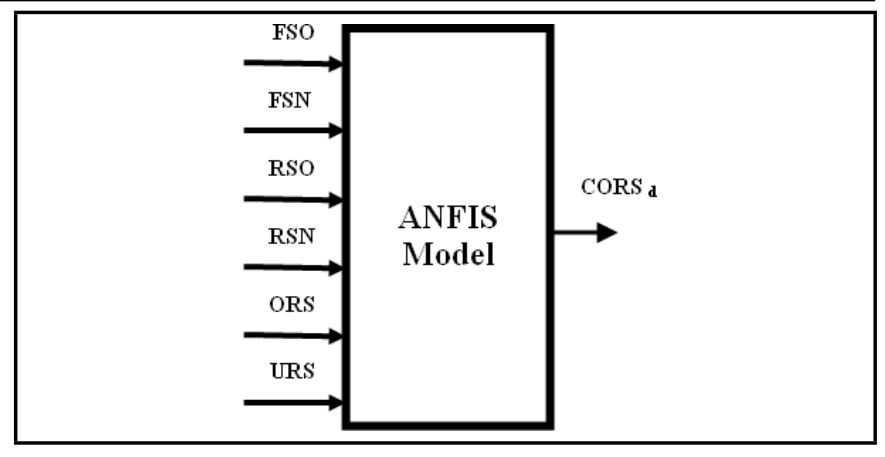

Figure 2. ANFIS model for the vehicle inputs.

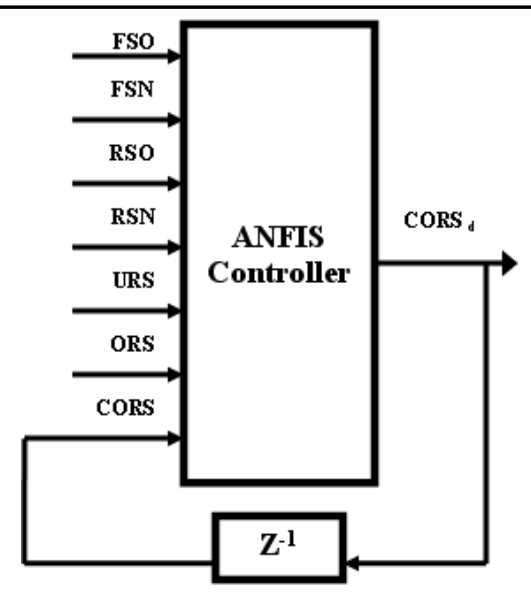

Figure 3. ANFIS controller for the seat.

ranges to fine tune the membership function. The offside front suspension vibration acceleration (FSO), nearside front suspension vibration acceleration (FSN), offside rear suspension vibration acceleration (RSO), nearside rear suspension vibration acceleration (RSN), vehicle seat pan vibration acceleration (ORS) and vehicle under seat (floor) vibration acceleration (URS) at previous step were used as inputs and controlled (desired) vehicle seat vibration acceleration $\left(\mathrm{CORS}_{\mathrm{d}}\right)$ from current step as output as seen in Fig. 3.

The ANFIS controller was developed using MATLAB software based on the experimental data sets. 3048 data samples were collected corresponding to vehicle speed of $10 \mathrm{~km} / \mathrm{h}$ ). These data was divided to 1524 points (odd number, where an odd number is number that cannot be divided evently by 2) for training and 1524 points (even number) for checking. ${ }^{17-20}$

\subsubsection{Development of Simulink model}

The simulink model for the control of the vehicle seat pan vibration acceleration was developed using MATLAB software. This Simulink model with the ANFIS controller was developed using the various toolboxes available in the Simulink library such as the power system, power electronics, control system, signal processing toolboxes and from its basic functions. The entire system modeled in Simulink is a closed loop feedback control system consisting of the NF forward model and the inverse ANFIS controller. The developed Simulink model for the control of various parameters of the NF controller is shown in Fig. 4. 


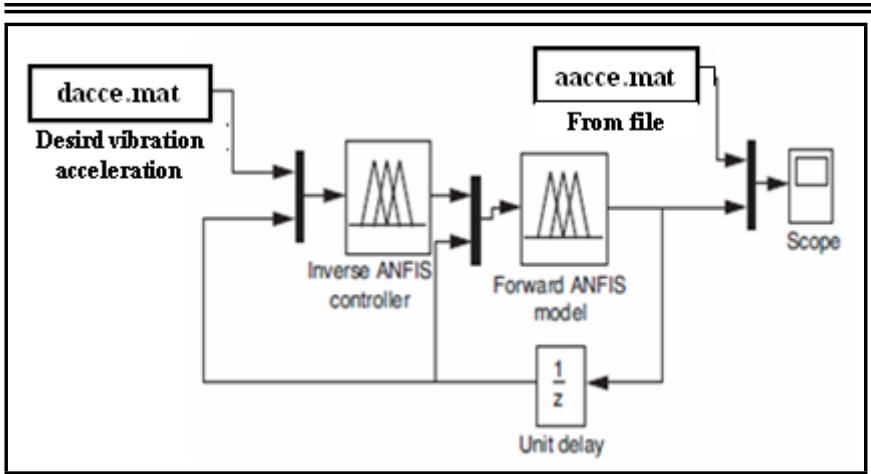

Figure 4. Block diagram of the Simulink of Neuro-Fuzzy controller.

\section{EXPERIMENTAL METHODOLOGY}

\subsection{Classical Passively Vehicle Suspension System}

The major purpose of any vehicle suspension system is to isolate the body from road unevenness disturbances and to maintain the contact between road and the wheel. Therefore, the suspension system is responsible for the ride quality and driving stability. The design of a classical passive suspension system is a compromise between this conflict demands. However, the improvement in vertical vehicle dynamics is possible by developing an air spring suspension system. Figure 5 shows the schematic diagram of the electric vehicle with air suspension system.

\subsubsection{Mechanical suspensions system}

The mechanical type suspension generally consists of spring and damper elements as shown in Figs. 6(a) and 6(b). No computer control is associated with this type of suspension. The suspension characteristics are fixed by the mass, spring, and damper elements, although some passive systems may have limited adjustments for the spring and/or damper elements. Passive suspensions do not automatically change or optimize their spring or damper characteristics based upon a changing environment. Therefore, they are most effective over a narrow range of disturbance inputs. The suspensions are designed based on a nominal mass load and disturbance environment expected to be most encountered over the design life of the suspension. The equivalent spring constant and damping coefficient of the mechanical suspension are $20000 \mathrm{~N} / \mathrm{m}$ and $1200 \mathrm{Ns} / \mathrm{m}$, where maximum travel $-25 \times 10^{-3} \mathrm{~m}$. These data have been originated based on the simulation presented in reference. ${ }^{1}$

\subsubsection{Air suspensions system}

In this paper, the separate functions of spring and damper were combined into a system that contained an air spring, valve, and accumulator. The sizing of the air spring and the accumulator provided the spring function, and the valve provided the damping function by controlling the air flow between the spring and the accumulator. A computer algorithm controlled the opening and closing of the valve to optimize the damping provided by the system.

For passive vibration suppression applications, the air spring's engineering function was the same as a steel spring,



Figure 5. Schematic diagram of the electric vehicle with air suspension system.

where a force was generated as a function of the displacement of the load. Since both air springs and steel springs contain relatively small amounts of damping, they were typically used in conjunction with separate dampers or shock absorbers. Although integrated air spring and damper units were available for some applications, as shown in Fig. 7(a), Fig. 7(b) shows the spring and damper functions were typically separate. In many cases, air or some other gas was the fluid medium for the air spring, and a hydraulic fluid was the medium for the damper.

Traditionally, the air suspension ball control system, the buoyancy of suspending comes from the wind-force from a DC fan. Once the floater reaching the setting height, the error signal is zero. The control signal will be zero soon and the DC fan will stop. If the floater was lower than the setting point, the control signal would restart the DC fan to lift the floater. However, the wind-power had to fill with the chamber first. Then, the additional wind-power rose to the tube to float up the floater. Due to the gravity of the floater and the physical dead-time of the fan, the floater would fall to the bottom of the tube in the time difference.

Therefore, a proper buoyancy to maintain the height of the floater was necessary. The equivalent spring constant and damping coefficient of the air bellow rubber diaphragm. The rubber diaphragm had to be thick enough to resist the force due to the pressure difference and payload. However, the introduced equivalent spring constant and damping coefficient were $300000 \mathrm{~N} / \mathrm{m}$ and $20000 \mathrm{Ns} / \mathrm{m}$ respectively, where maximum travel $-25 \times 10^{-3} \mathrm{~m}^{1}$

\subsection{Experimental Setup}

Figure 8 shows photograph of a sample from the vibration measurement on the mechanical suspension system, while Fig. 9 shows the recording and analysis instrumentation.

The test vehicle was a one-passenger fabricated electric vehicle prototype, where its working conditions were set at constant speed of $10 \mathrm{~km} / \mathrm{h}$. The road surface used in this study was 


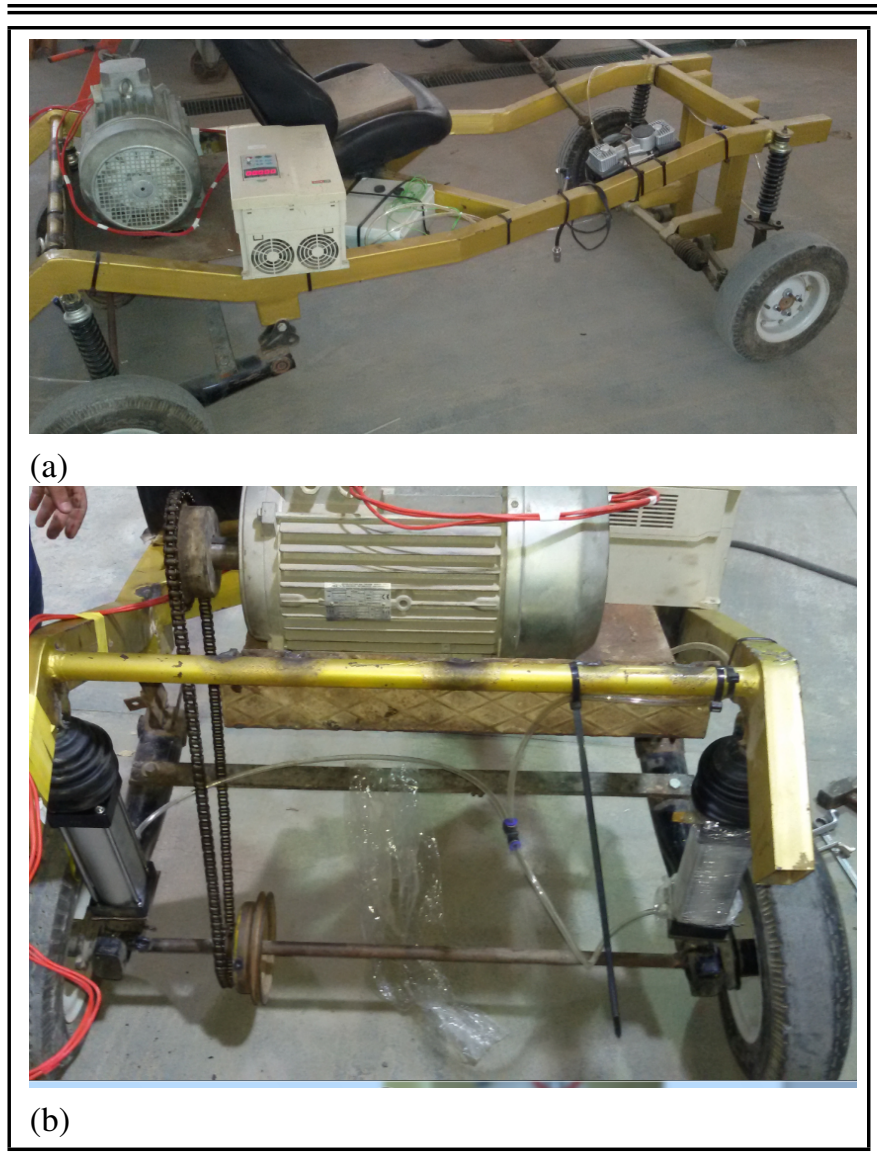

Figure 6. (a) Vehicle rear. (b) Vehicle front.
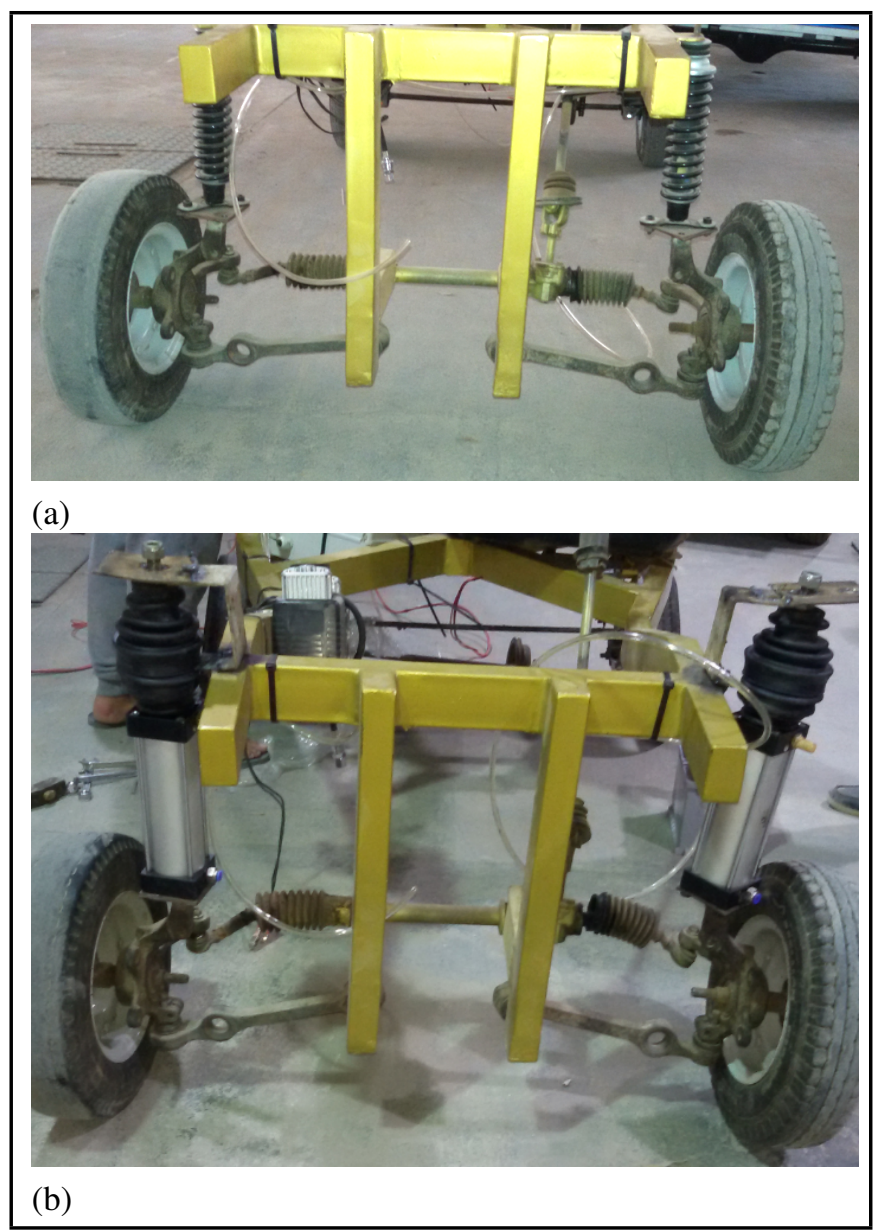

Figure 7. (a) Vehicle rear. (b) Vehicle front.

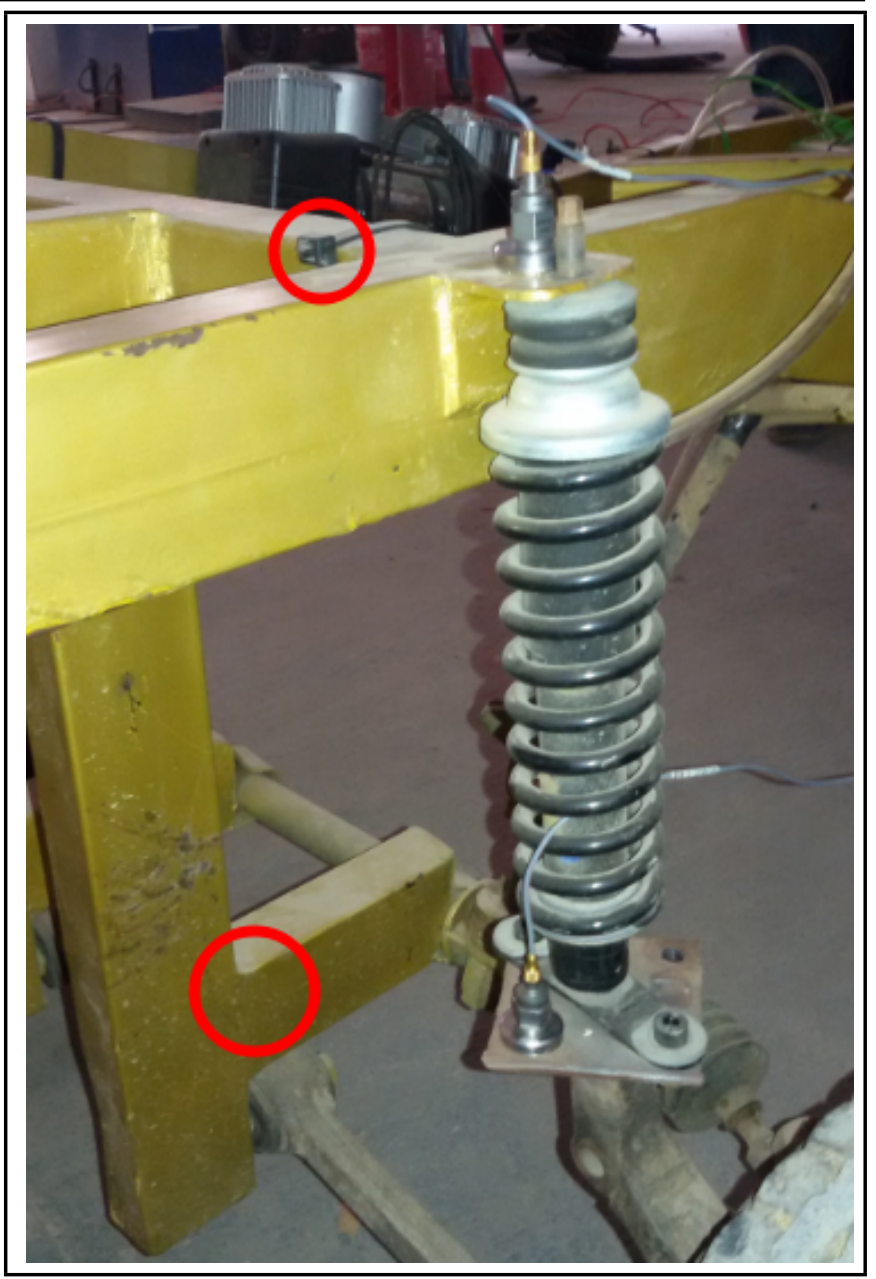

Figure 8. The accelerometers positions.

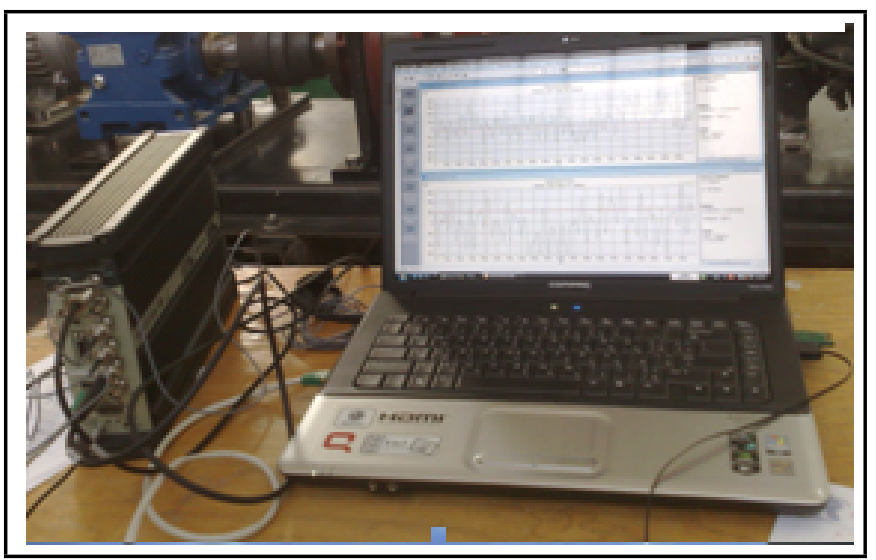

Figure 9. The vibration measurement system.

paved concrete texture, where its characteristics had no wear or weathering, small stones, a smooth surface, low overall vibration level and higher frequency greater proportion of noise, and no "roar". Figure 10 shows photographs for this road surface and the vehicle was driven at $10 \mathrm{~km} / \mathrm{h}$, where GPS sensor was used for the measurement of vehicle speed which provides an accurate information of the speed of the vehicle estimated through the Doppler's effect.

The vibration measurements were made on the road surface mentioned above and the vibration samples were acquired with an integration period of 1.0 second and each individual mea- 


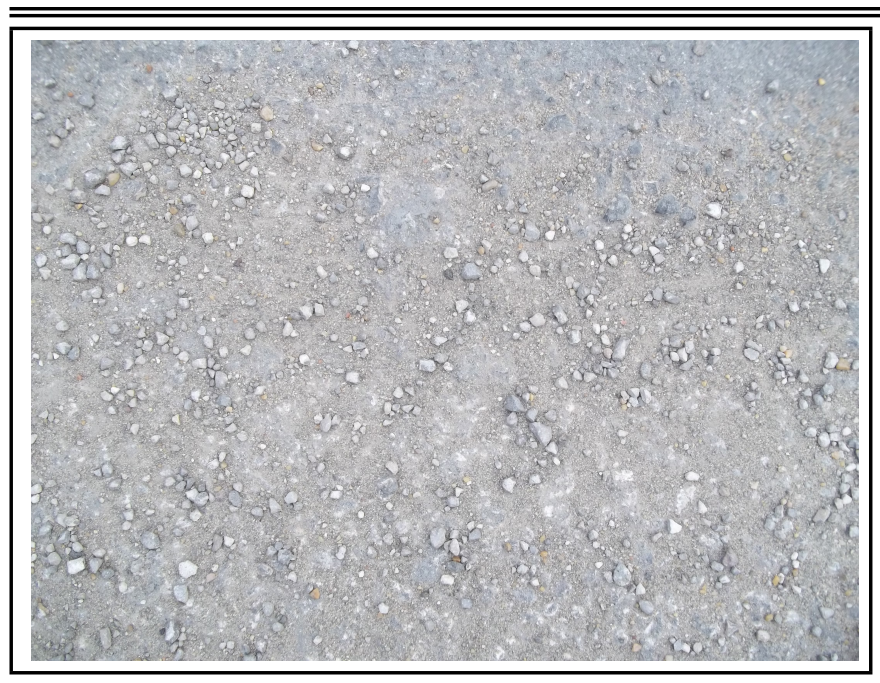

Figure 10. Paved concrete texture road surface.

surement with a 10 second duration using a multi-channel analyser. Unweighted accelerations on the vehicle seat base (floor) and on the passenger seat pan were measured with Bruel \& Kjaer accelerometers Type 4514B-001. The vibration amplitudes recorded from the seat base (floor) and on the passenger seat pan during travel were investigated for possible artifacts and any unclear signals that were detected were removed. The accelerometer must move with the interface, they must not alter the dynamic properties of either the vehicle seat pan or the passenger body and it must offer little impedance to movement over the frequency range of interest. For this reason, a thin disc of $0.25 \mathrm{~m}$ in diameter was used (seat interface for accelerometer indicating passenger body acceleration received). It was a rigid device that compressed the seat in the same manner as a passenger's buttocks. As only the vertical direction was considered, only vertical accelerations were measured. Under each working condition, the vibration signals at the vehicle floor and the passenger body/seat were analysed by using the a Bruel \& Kjaer portable, multi-channel PULSE, Type 3560B-X05 analyser, Bruel \& Kjaer PULSE labshop, and the measurement software type 7700 and saved in the computer. Figure 11 presents a schematic of the measurement assembly.

\section{RESULTS AND DISCUSSION}

Figures 12(a) and 12(b) show the experimental raw signals of the vibration acceleration in terms of time history results taken at the connection of unsprung and sprung points on the left hand side (LHS) and right hand side (RHS) of the vehicle while Fig. 12(c) shows the corresponding raw signals the vibration acceleration in terms of time history results taken on the vehicle floor (seat base) and seat pan based on the measurement methodology presented in section 4. Figure 12(d) shows frequency domain by comparatively presenting raw and weighted floor acceleration for the vehicle when equipped by mechanical. Figures 13 (a) to 13 (c) show the results of the same parameters at the same points when the vehicle was equipped with an air suspension system. The road surface is being paved concrete texture and at vehicle speed of $10 \mathrm{~km} / \mathrm{h}$. Figure 13(d) shows frequency domain comparatively by presenting raw and weighted floor acceleration for the vehicle

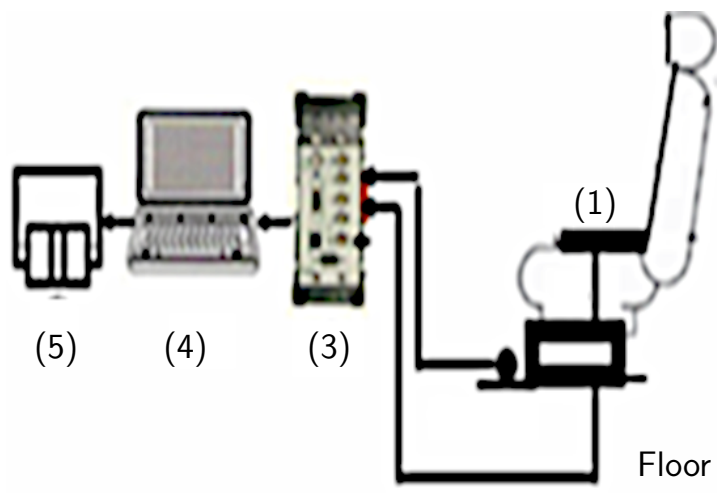

(2)

(1) - Seat Accelerometer

(2) - Vehicle Floor Accelerometer

(3) - MultiChannel Analyser (PLUS)

(4) - Computer (Lab Shop)

(5) - Printer

Figure 11. Schematic representation of experimental setup.

when equipped by air suspension system.

The developed ANFIS model structure with two input neurons and one output neuron along with four hidden layers (input membership function, rule base, membership function, and aggregated output), which are shown in Fig. 2. 2048 data points from experimental data are used to validate the accuracy of the forward model. Figures 14(a) and 15(a) show the comparisons between the vehicle's seat measured and predicted vibration accelerations based on the ANFIS model in terms of time-history for the mechanical and air suspension system respectively. The predicted vibration acceleration can track the target vibration acceleration very well. The experimental data belonged to speeds of $10 \mathrm{~km} / \mathrm{h}$. The training of the neural network by using the fuzzy rule base for selection of proper and optimal rule is considered in the next section (designed ANFIS controller).

Figures 14(b) and 15(b) show the comparisons between the vehicle' seat measured; and predicted vibration accelerations based on the ANFIS controller in terms of time-history for the mechanical and air suspension system respectively. The predicted vibration acceleration can track the target vibration acceleration very well. The experimental data belonged to speeds of $10 \mathrm{~km} / \mathrm{h}$. It is observed from the analysis of results in the figures that, by using the ANFIS controller, the vehicle seat vibration acceleration controlled reaches an acceptable error values. It is also observed that, with the designed neuro-fuzzy controller, the vehicle seat vibration acceleration characteristics curves take less time to settle with the system stabilization because of the training process of the ANN used and the proper selection of the rule base. ${ }^{19}$

The conditions during the tests are illustrated in the previous figures. Perhaps the most powerful analysis technique is the frequency-domain analysis (FFT) for the following reasons:

1. Changes in minor spectral components, which may be the first indication of incipient failure, will not always affect 


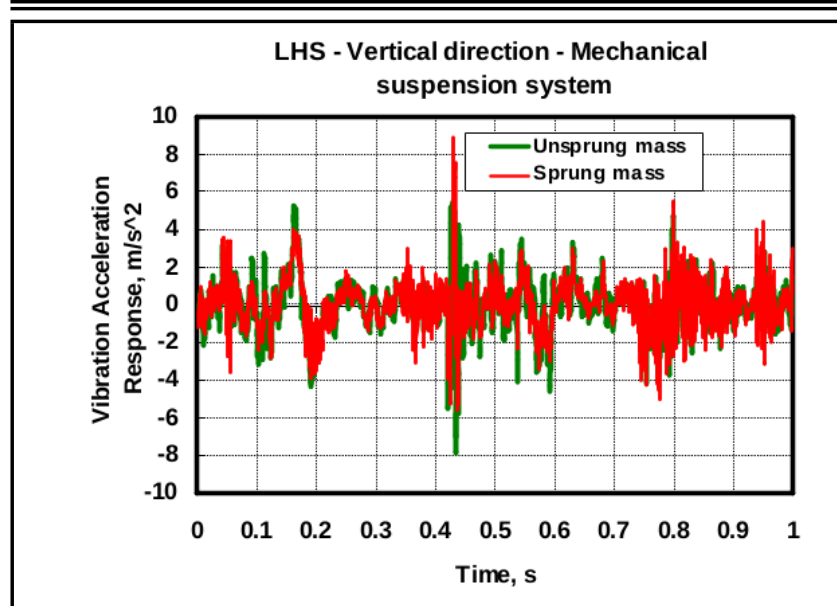

(a) Time history spectra on the vehicle LHS RHS - Vertical direction - Mechanical suspension system

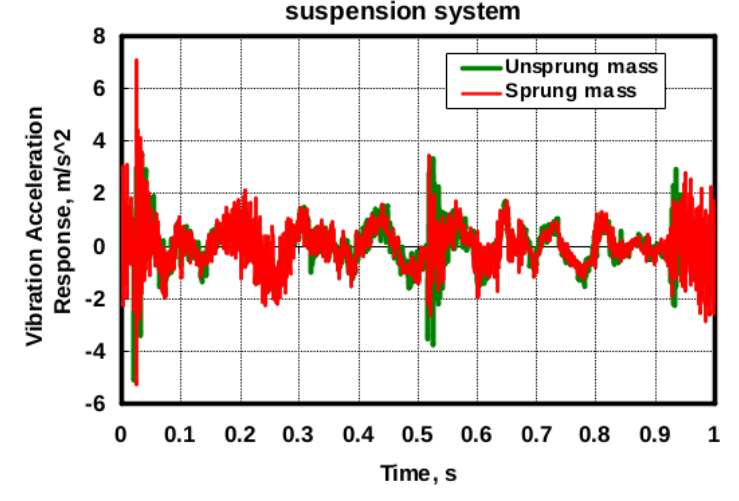

(b) Time history spectra on the vehicle RHS Seat pan - Vertical direction - Mechanical suspension system

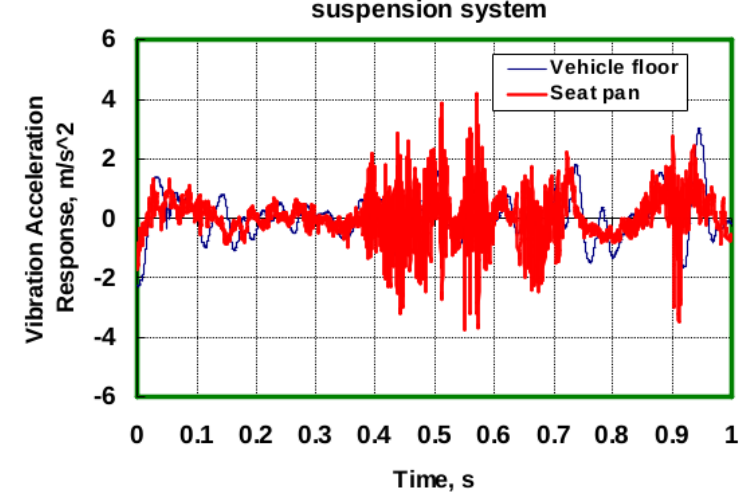

(c) Time history spectra on the vehicle seat pan Mechanical suspension system, Vertical direction, Vehicle speed $10 \mathrm{~km} / \mathrm{h}$

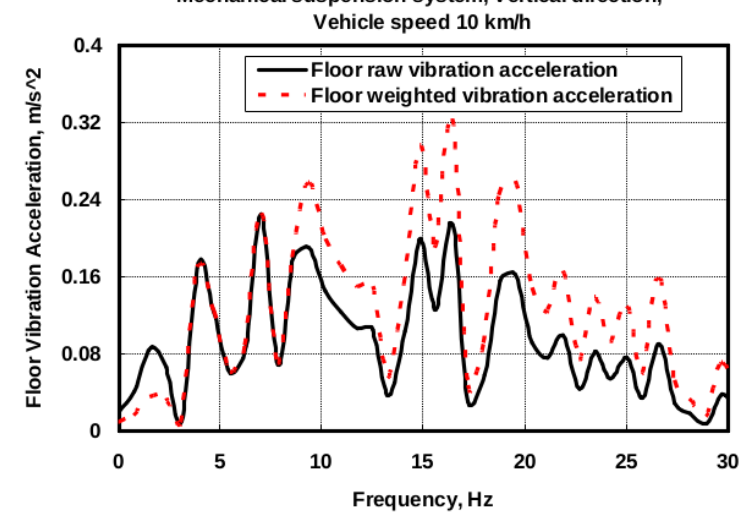

(d) Frequency-domain spectra on vehicle floor

Figure 12. Vehicle vibration acceleration - mechanical suspension system.

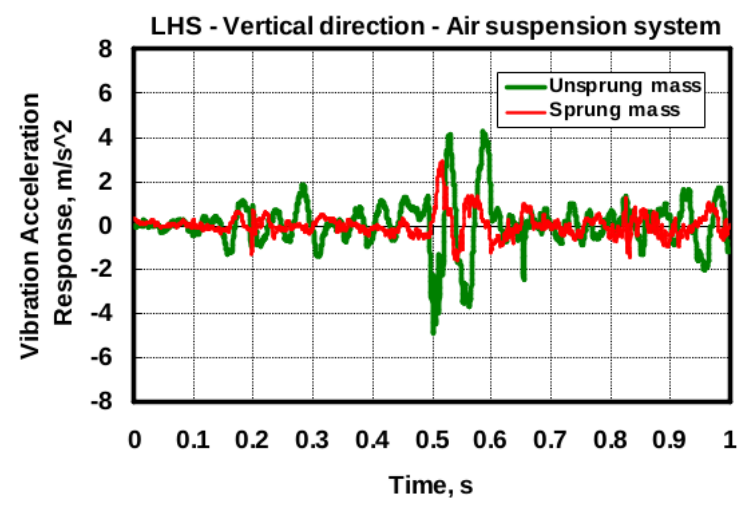

(a) Time history spectra on the vehicle LHS

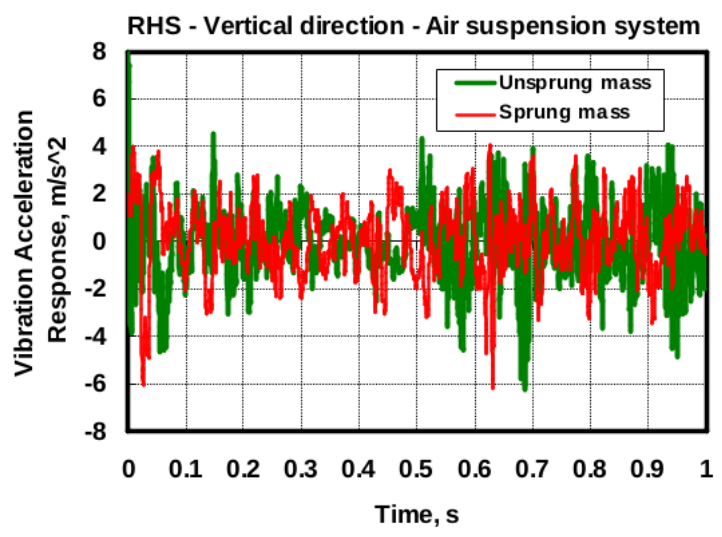

(b) Time history spectra on the vehicle RHS

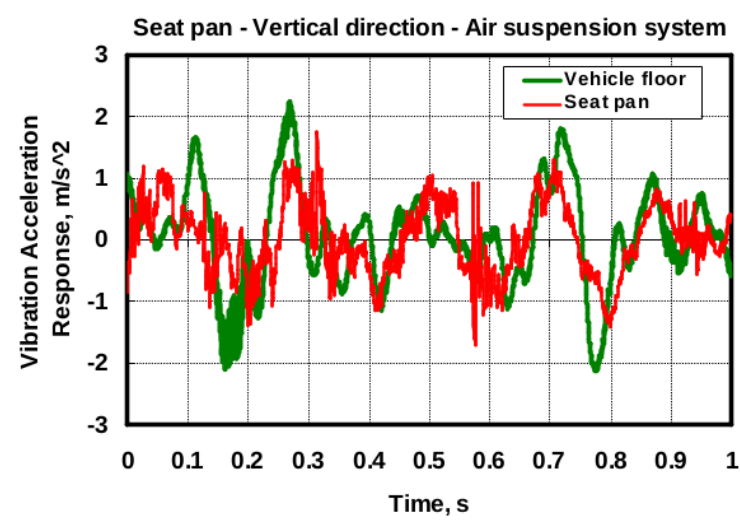

(c) Time history spectra on the vehicle seat pan

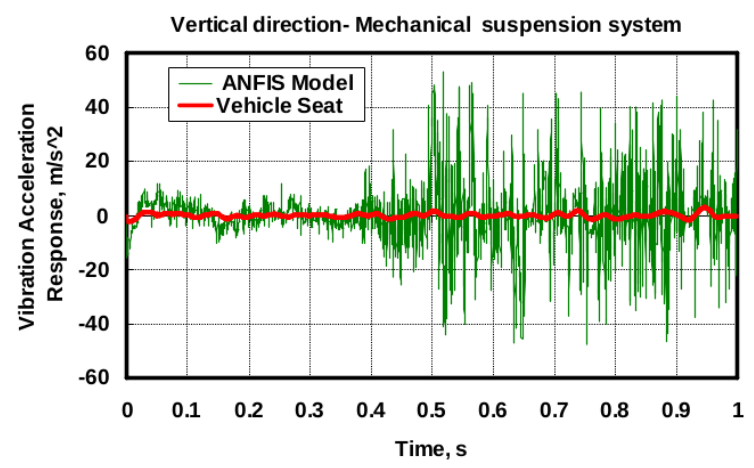

(d) Frequency-domain spectra on vehicle floor

Figure 13. Vehicle vibration acceleration — air suspension system. 


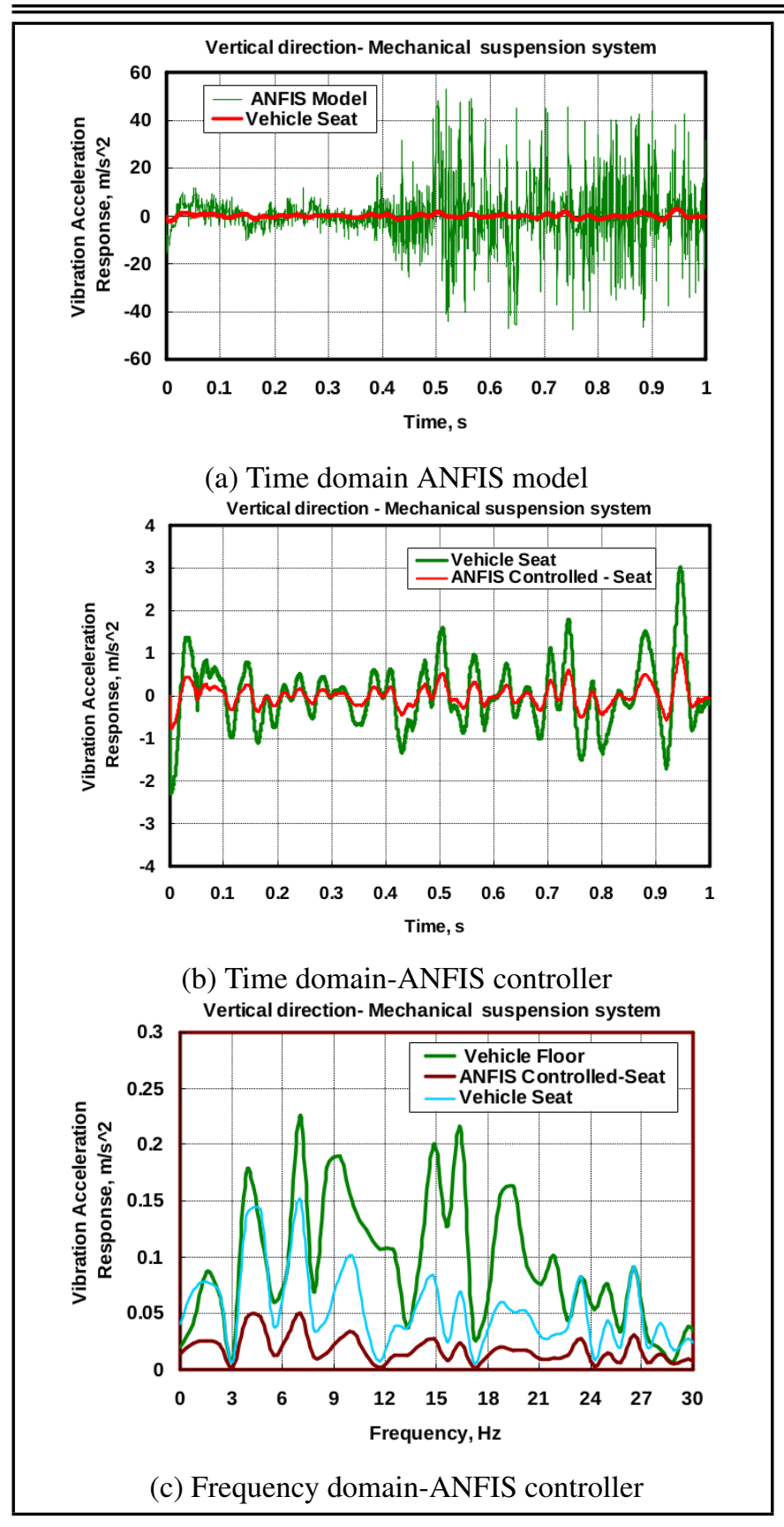

Figure 14. Comparisons between the vehicle floor and seat measured; and seat predicted.

the overall vibration level. These changes can be picked up by spectrum monitoring.

2. A rise in overall level indicates that something has been changed but does not give any information regarding the source. This will often be indicated by the frequency at which the change occurs.

In Figs. 14(c) and 15(c), the FFT of weighted vibration acceleration measurements in vertical direction were truncated to show the frequency range of interest up to a $30 \mathrm{~Hz}$ clarity for the vehicle floor, seat, and seat controlled by ANFIS for both mechanical and air suspension system respectively. In both figures, a good seat should have a peak frequency of at least 1.4 times lower than the peak frequency of the vehicle where the seat is mounted (uncontrolled), but for the ANFIS - a seat should have a peak frequency of at least 2.8 times. In the

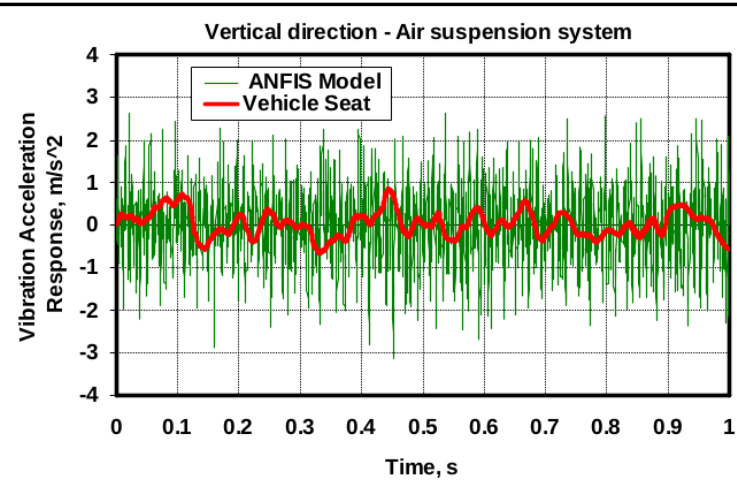

(a) Time domain ANFIS model

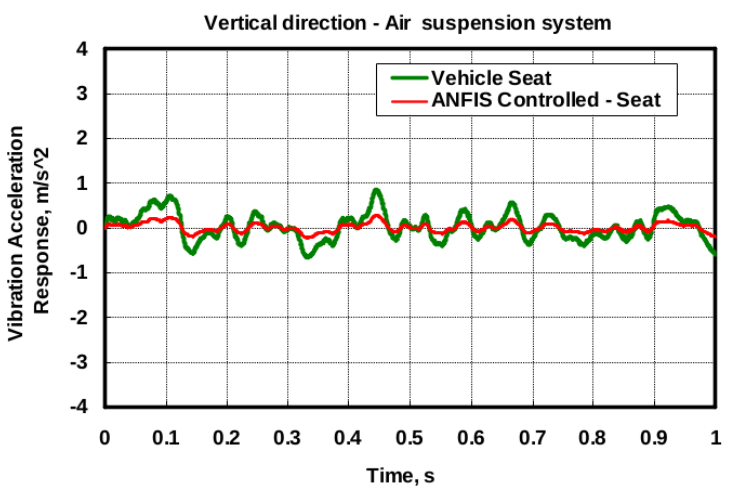

(b) Time domain-ANFIS controller

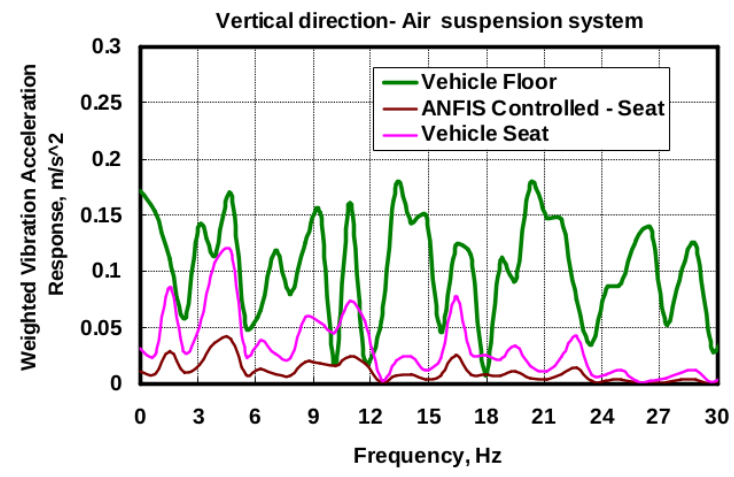

(c) Frequency domain-ANFIS controller

Figure 15. Comparisons between the vehicle floor and seat measured; and seat predicted.

present study, it is noticed that the weighted vibration acceleration at the peak frequency for either a seat or the ANFIS-seat is amplifying rather than attenuating due to poor design and improper maintenance of seat. Therefore, it could be possible that the main source of discomfort.

Table 1 tabulates the floor vibration signal parameters calculated values of crest factor (CF) kurtosis (kur) and the international road roughness (IRI) based on Eqs. (1) to (3) respectively. According on the data presented in the figures and table, it can be observed that the $\mathrm{CF}$ values ranged from 3.87 (mechanical) to 3.38 (air). On the other hand, the kurtosis value of approximately 3.0 (3.07 air) is for a Gaussian distribution. Higher kurtosis of (4.45 mechanical) indicates the existence of numerous extreme data values, inconsistent with a Gaussian distribution. Moreover, the international road roughness (IRI) values are proportional to kurtosis values which indicate that 


Table 1. Floor Vibration Signal Parameters.
\begin{tabular}{|l|l|l|l||}
\hline \multicolumn{3}{|c||}{ Vehicle Suspension System Types } \\
\hline \multicolumn{2}{||l|}{ Mechanical Suspension System } & \multicolumn{2}{c|}{ Air Suspension System } \\
\hline Floor Vibration Signal Parameters & Floor Vibration Signal Parameters \\
\hline Crest factor, CF & 3.87 & Crest factor, CF & 3.38 \\
\hline $\begin{array}{l}\text { Kurtosis of vibration } \\
\text { signals, Kur }\end{array}$ & 4.45 & $\begin{array}{l}\text { Kurtosis of vibration } \\
\text { signals, Ku }\end{array}$ & 3.07 \\
\hline $\begin{array}{l}\text { Road roughness } \\
\text { index, IRI }\end{array}$ & 13.6 & $\begin{array}{l}\text { Road roughness } \\
\text { index, IRI }\end{array}$ & 9.38 \\
\hline
\end{tabular}

Table 2. SEAT Components.

\begin{tabular}{||c|c|c|c|c||}
\hline \multicolumn{5}{|c|}{ Vehicle Suspension System Types } \\
\hline & \multicolumn{2}{|c|}{$\begin{array}{c}\text { Mechanical } \\
\text { Suspension System }\end{array}$} & \multicolumn{2}{c|}{ Suspension System } \\
\hline $\begin{array}{l}\text { SEAT } \\
\text { Components }\end{array}$ & $\begin{array}{c}\text { RMS u } \\
\left(\mathrm{m} / \mathrm{s}^{2}\right)\end{array}$ & $\begin{array}{c}\text { RMS c } \\
\left(\mathrm{m} / \mathrm{s}^{2}\right)\end{array}$ & $\begin{array}{c}\text { RMS u } \\
\left(\mathrm{m} / \mathrm{s}^{2}\right)\end{array}$ & $\begin{array}{c}\text { RMS c } \\
\left(\mathrm{m} / \mathrm{s}^{2}\right)\end{array}$ \\
\hline $\begin{array}{l}\text { Floor RMS - } \\
\text { Uncontrolled }\end{array}$ & 0.1475 & 0.1475 & 0.2741 & 0.2741 \\
\hline $\begin{array}{l}\text { Seat RMS - } \\
\text { Uncontrolled }\end{array}$ & 0.0791 & - & 0.0498 & - \\
\hline $\begin{array}{l}\text { Seat RMS - } \\
\text { Controlled }\end{array}$ & - & 0.0270 & - & 0.0173 \\
\hline $\begin{array}{l}\text { Exposure period, } \\
T_{0.825 A(8)}(\mathrm{h})\end{array}$ & 870.536 & 7464.022 & 2196.043 & 2571.270 \\
\hline SEAT, \% & 53.601 & 18.305 & 18.168 & 6.306 \\
\hline
\end{tabular}

a human perceives more peaks and impulses when driving on road surfaces with greater roughness. Generally, the values of crest factor $(\mathrm{CF})$ and kurtosis (kur) for the vehicle equipped by air suspension system are lower than those for the vehicle equipped by mechanical suspension system.

In Table 2, since the fabricated vehicle produces low amounts of shocks (crest factor less than 6) and as time dependency is incorporated in weighted RMS. Therefore, the RMS will be used to evaluate the SEAT ratio rather than VDV. The calculated weighted RMS value and exposure period $\left(T_{0.825 A(8)}\right)$ for the vehicle seat weighted vibration acceleration based on Eqs. (4) and (5) are presented in Table 2, where their values are lower for air suspension than mechanical suspension. On the other hand, the weighted RMS controlled values by the ANFIS are lower than the uncontrolled values while the exposure period $\left(T_{0.825 A(8)}\right)$ controlled values by the ANFIS are higher than the uncontrolled values.

In terms of seat effective amplitude transmissibility (SEAT), estimations based on Equ. (6) and RMS values are used to make a comparison between the types of suspension system, where the SEAT for the fabricated vehicle with air suspension behaves lower value than that for the fabricated vehicle with mechanical suspension either seat RMS uncontrolled or controlled (See Table 2).

\section{CONCLUSIONS}

Several different analysis methods have been discussed, all of which involve capturing the acceleration at the seat (and/or floor) of the vehicle. Some of the techniques include methods to calculate expected passenger's comfort from the vibration magnitudes measured. Most techniques give results that indicate that the vibration in vehicles is not severe but could occasionally cause some discomfort.

The ANFIS can be used with systems handling more complex parameters. Another advantage of the ANFIS is that its speed of operation is much faster than the other control strategies; the tedious task of training membership functions is done in ANFIS. Collectively, these results show that the ANFIS controller provides faster settling times, has very good dynamic response and good stabilization. A simulink model was developed in Matlab software with the ANFIS controller for the vehicle seat weighted vibration acceleration control. The control strategy was also developed by writing set of fuzzy rules according to the ANFIS control strategy with the backpropagation algorithm in the back end.

The influence of vibration on comfort is generally known and the consequent origination or even deterioration of health. It must be kept in mind that low frequency vibration has essentially higher energy severity than a vibration of middle and higher frequencies. The long-term exposition of the energy rich low frequency vibration can potentially cause harm to human health, and not only the health but also functionality of other organs such as the central nervous system. Therefore, it is important to improve the criteria of energy rich, low frequency, vibration assessment by means of control by any control strategy so that the influences of energy on human health and comfort are assessed correctly.

The predicted vibration acceleration can track the target vibration acceleration very well. Moreover, the values of crest factor and kurtosis for the vehicle equipped by air suspension system are lower than those for the vehicle equipped by mechanical suspension system. Furthermore, the seat effective amplitude transmissibility for the fabricated vehicle with air suspension behaves lower value than that for mechanical suspension.

In terms of seat effective amplitude transmissibility (SEAT), an estimation based on weighted root mean square (RMS) is used to make a comparison between the vehicle equipped by either mechanical or air suspension system. For the assessment of vibration, with strong low frequency content, in the frequency range from up to $30 \mathrm{~Hz}$, it is more logical to use SEAT estimation based on weighted RMS.

\section{REFERENCES}

1 Sekulić, D. and Dedović, V. The effect of stiffness and damping of the suspension system elements on the optimization of the vibrational behaviour of a bus, International Journal for Traffic and Transport Engineering, 1(4), 231-244, (2011).

2 Fongue, W. A., Pelz, P. F. and Kieserling, J. The dynamic performance of air spring air damping systems by means of small excitations, Proceedings of ISMA2012-USD2012, 3891-3902, (2012).

3 Hongguang Li, Guo, K., Shuqi Chen, S., Wang, W. and Cong, F. Design of stiffness for air spring based on ABAQUS, Mathematical Problems in Engineering 2013, Article ID 528218, 5 pages, (2013). https://dx.doi.org/10.1155/2013/528218

${ }^{4}$ LEE, S. J. Development and analysis of an air spring model, International Journal of Automotive Technology, 
11(4), 471-479, (2010). https://dx.doi.org/10.1007/s12239010-0058-5

5 Yina, Z., Khajepourb, A., Caoc, D., Ebrahimib, B. and Guod, K. A new pneumatic suspension system with independent stiffness and ride height tuning capabilities, Vehicle System Dynamics, 50(12), 1735-1746, December (2012). https://dx.doi.org/10.1080/00423114.2012.660167

6 Hostens, I., Deprez, K. and Ramon, H., An improved design of air suspension for seats of mobile agricultural machines. Journal of Sound and Vibration 276, 141-156, 2004. https://dx.doi.org/10.1016/j.jsv.2003.07.018

7 Abouel-Seoud, S. A. Assessment of passenger ride comfort during vertical vibration of mid-size saloon and off-road vehicles on asphalt roads, International Journal of Vehicle Structures \& Systems, 5(1), 39-46, (2014).

8 Eskandary, P. K, Khajepour, A., Wong, A. and Ansari, M. Analysis and optimization of air suspension system with independent height and stiffness tuning, International Journal of Automotive Technology, 17(5), 807-816, (2016). https://dx.doi.org/10.1007/s12239-016-0079-9

9 Jin, L. Yu, Y and Fu, Y. Study on the ride comfort of vehicles driven by in-wheel motors, Advances in Mechanical Engineering 2016, 8(3), 1-9, (2016). https://dx.doi.org/10.1177/1687814016633622

10 British Standards Institute, BS 6841-1987. Measurement and evaluation of human exposure to whole-body vibration and repeated shock, (1987).

11 International Standard Organization, ISO 2631/1-1985. Evaluation of human exposure to whole-body vibration, Part 1: General requirements, (1985).

12 Ahlin, K., Tech, S. E. and Granlund, J. International roughness index, IRI, and ISO 2631 vibration evaluation. Washington DC: Transportation Research Board, USA, (2001). https://dx.doi.org/10.1016/0022-460X(80)90305-3

13 Lewis, C. H and Griffin, M. J. Predicting the effects of vertical vibration frequency combinations of frequencies and viewing distance on the reading of numeric displays, Journal of Sound and Vibration, 20, 355-377, (1980). https://dx.doi.org/10.1016/0022-460X(80)90305-3
14 Watany, M., Eltantawie, M. A. and. Abouel-seoud, S. A. Application of an adaptive neuro-fuzzy Inference system for low speed planetary gearbox vibration control. Journal of Low Frequency Noise, Vibration Active Control, 34(3), 323-342, (2015). https://dx.doi.org/10.1260/02630923.34.3.323

15 Takagi, T. and Sugeno, M. Derivation of fuzzy control rules from human operator's control action, in Proc. IFAC Symp. Fuzzy Inform. Knowledge Representation and Decision Analysis, 55-60, July (1983). https://dx.doi.org/10.1016/S1474-6670(17)62005-6

16 Abouel-Seoud, S. A. Active control analysis of passenger vehicle interior noise produced from tyre/road interaction, International Journal of Vehicle Noise and Vibration, 12(2), 138-141, (2016). https://dx.doi.org/10.1504/IJVNV.2016.079052

17 Jang, J. S. R. Neuro-fuzzy and soft computing, A computational and learning and machine Intelligence, Prentice Hall, (1997).

18 Jang, J.S.R ANFIS: Adaptive-network-based fuzzy inference systems., IEEE Trans. on Syst., Man and Cybern., 23(3), 665-684, May/June (1993). https://dx.doi.org/10.1109/21.256541

19 Kusagur, A., Kodad, S. F., and Ram, B. S. Design and simulation of an adaptive neuro-fuzzy inference system (ANFIS) for speed control of induction motor, International Journal of Computer Applications (2010), 6(12), 29-44, (2010).

20 Jang J. S. R., Input selection for ANFIS learning. Proceedings of the Fifth IEEE International Conference on fuzzy System (1996), New Orleans (USA), 2, 1493-1499, 8-11, September (1996). https://dx.doi.org/10.1109/FUZZY.1996.552396

21 Elbeheiry, E.M., Karnopp, D.C., Elaraby, M.E. and Abdelraaouf, A.M., Advanced Ground Vehicle Suspension Systems \pm A Classi®ed Bibliography. Vehicle System Dynamics 24, 231-258, (1995). https://dx.doi.org/10.1080/00423119508969089 